\title{
Florestan Fernandes e o radicalismo plebeu em Sociologia
}

\author{
GABRIEL COHN
}

$\mathrm{E}$ M 1945, o jovem Florestan Fernandes escreveu um texto que viria a ser um dos artigos mais lidos da fase etnológica de sua carreira. Relatava ele a vida do índio bororo Tiago Marques Aipobureu, caso exemplar daquilo que a literatura sociológica da época denominava homem marginal, situado entre duas culturas, sem pertencer a nenhuma delas. Trata-se daquela figura a que se aplica frase de timbre inconfundível do grande discípulo de Florestan que foi Octávio Ianni (na medida em que Florestan teve discípulos, e na medida em que Ianni aceitasse essa condição em relação a pessoa alguma, mesmo o mestre que deveras admirava). Perguntado acerca de amigo que se revelava perturbado e confuso, Ianni (que não invoco aqui por acaso) explicou, com o sorriso maroto e compassivo que o caracterizava: "Ele estava aqui, e foi para lá; mas parece que sua alma não está nem aqui, nem lá”. Também naquele texto de Florestan sobre um homem em busca da sua identidade pode-se discernir um traço que raramente as-

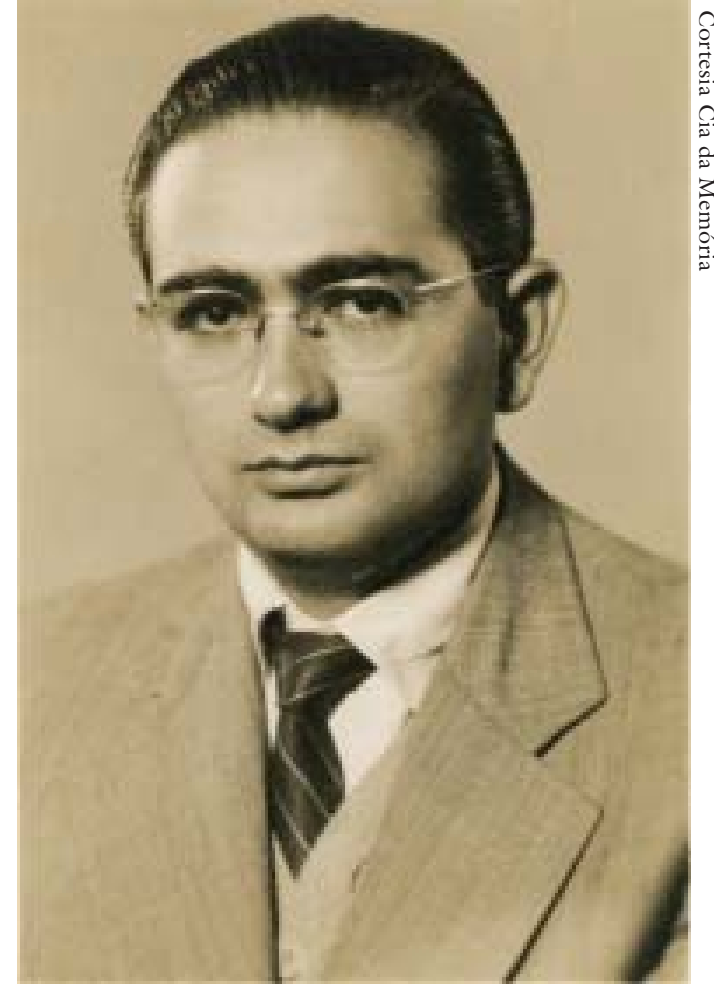

Florestan Fernandes (1920-1995) somava na sua escrita disciplinada e severa: uma profunda simpatia humana pelo personagem, tal como somente se repetiria nos retratos da vida de populações negras perdidas entre a escravidão despótica e a liberdade abandonada, naquela que talvez seja a sua mais bela obra, sobre a integração do negro na sociedade de classes.

$\mathrm{O}$ aspecto pungente da situação de Tiago consistia, claro, em ele não ser um bororo marginal no mundo dos brancos mas sim, tendo retornado ao seu mundo social de origem, ter-se convertido em marginal no seu povo. É nessa trama de referências culturais frustadas que ele é levado a sempre procurar sua alma do lado errado. Dificilmente essa experiência da busca de identidade nos 

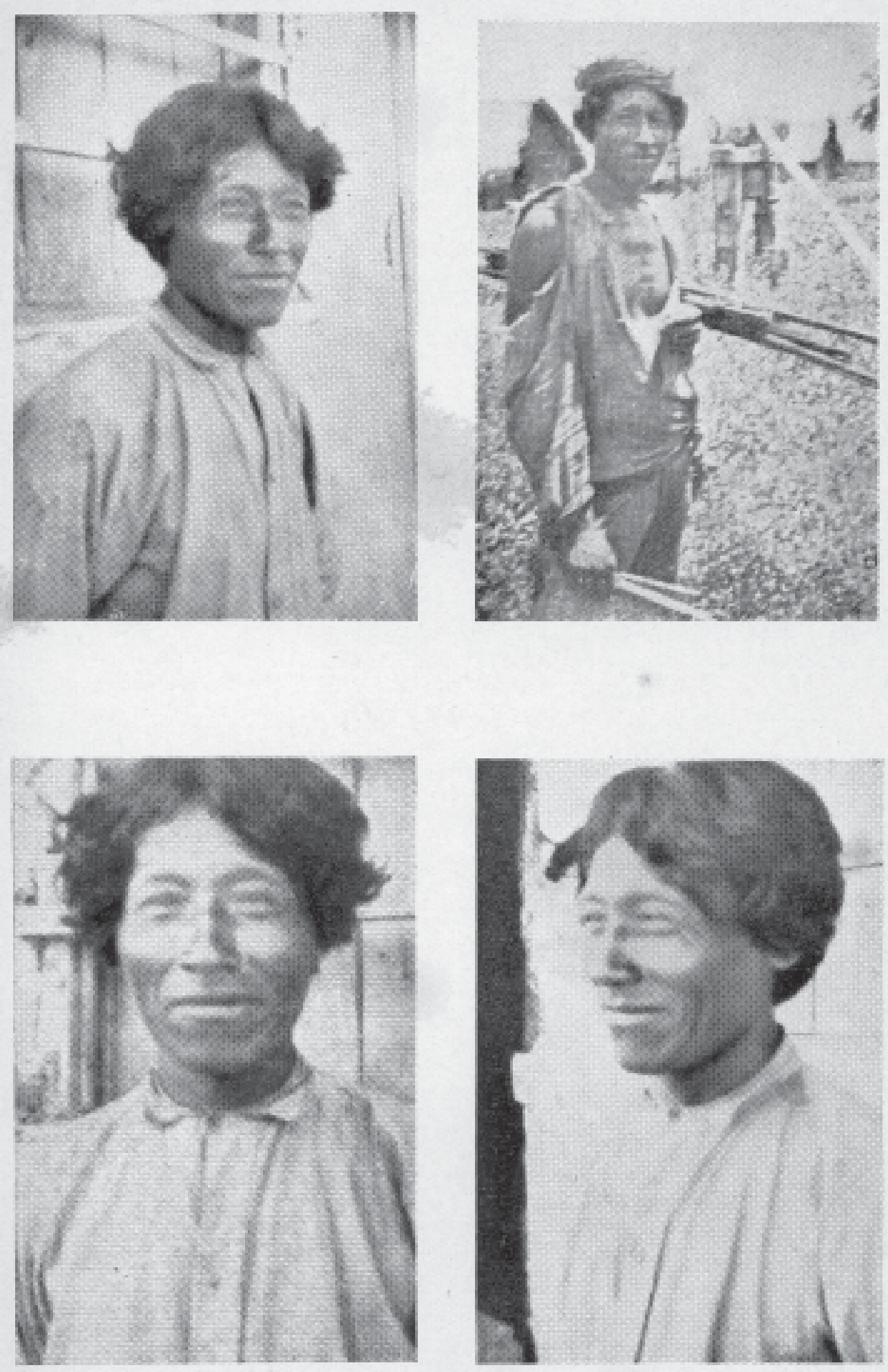

Fotografias do indio bororo Tiago Marques Aipobureu:

"caso exemplar daquilo que a literatura sociológica da época denominava homem marginal". 
interstícios de dois mundos terá deixado indiferente o jovem cientista em formação aos 25 anos, quando ele próprio procurava o seu lugar em condições difíceis. Aqui, porém, já podemos encontrar os traços básicos da trajetória que Florestan buscaria imprimir à sua vida, tal como se exprimiria na sua produção intelectual e na sua inserção na vida pública. Longe de espelhar-se de algum modo no dilaceramento do seu personagem, Florestan parece ter encontrado neste objeto de pesquisa, como depois saberia encontrar em tantos outros, uma advertência, um desafio e um programa de trabalho. A advertência seria contra qualquer incorporação autocomplacente das vicissitudes da própria biografia na conduta efetiva na vida; o desafio consistiria em dinamizar (para usar um dos seus termos prediletos), em preencher criativamente de energia as formas de percepção do mundo e as alternativas de ação que sua experiência própria iria descortinando; o programa de trabalho, finalmente, se traduziria na resolução de, confrontado com alternativas que se apresentassem como exclusivas e que poderiam paralisá-lo na escolha desse ou daquele papel a ser desempenhado, optar sempre por preencher a ambos, saturando-os (outro termo predileto seu) com seus significados próprios. Nenhuma concessão ao refluxo à subjetividade, pois, mas busca insaciável de aprendizado e de sentido para a ação em tudo que o mundo lá fora oferecesse. Uma posição, em suma, fundamentalmente plebéia perante o mundo: enérgica, intransigente, sobretudo insaciável no empenho em apreender (outro dos seus termos) no pensamento e na ação tudo o que o novo mundo social lhe sonegava. Por detrás disso está aquilo que dará a marca distintiva ao trabalho de Florestan: é nesses mesmos termos que ele conseguiria organizar, mais uma vez, de modo criativo, enérgico e voltado para a saturação dos conteúdos, a sua percepção sociológica e histórica do mundo, também nas grandes análises em nível macro a que dedicaria sua obra madura. Tudo isso no contexto biográfico da contínua busca de "saturar de sentido" os "papéis" que identificava como constitutivos do seu trabalho, expressos com inteira nitidez e com clara indicação da sua intrincada rede de relações na abertura de escrito de 1954, sobre relações culturais entre o Brasil e a Europa, ao se apresentar como "um brasileiro que é sociólogo por profissão e socialista por convicções políticas".

Essa passagem de uma visão pessoal socialmente condicionada para um programa de pesquisa ganha forma numa peculiar modalidade de absorção e criação conceitual. Em primeiro lugar (de novo, uma construção que evoca o estilo de Florestan: sua colega e amiga, a antropóloga Gioconda Mussolini, dizia que nos seus escritos sempre transparecia um quadro sinótico - em primeiro lugar, em segundo lugar, por um lado, por outro lado), isso se manifesta no predomínio de uma específica imaginação espacial sobre a dimensão temporal nas análises. Esse mestre da reconstrução histórica vê o passado não como um fluxo, mas como um campo de oportunidades que numa configuração determinada se abriam à ação racional e consciente dos homens, assim como o presente é um campo de forças em pugna pela dinamização e efetivação de tendências estruturais, e o futuro é um conjunto de possibilidades suscetíveis, em grau que 
compete à análise avaliar, de intervenção com base nas condições presentes. Sobretudo, a referência ao passado jamais é feita nos termos de um jogo da memória (como em Gilberto Freyre, seu grande antípoda): é muito mais um inventário de obstáculos na construção do presente e na projeção para o futuro.

A ênfase nos obstáculos estruturais no lugar da rememoração descansada das raízes de que brota a experiência social vivida encontraria ressonância decisiva nas concepções de outro grande sociólogo marginal, igualmente preocupado com a institucionalização da ciência social na sua sociedade de referência. Refirome, é claro, a Émile Durkheim, em quem igualmente uma energia voluntariosa impregnava análises do mais sóbrio cunho funcional e estrutural. A ele deve-se uma das chaves do arsenal analítico de Florestan, na idéia de que, dado um certo tipo de organização da sociedade, ele tende intrinsecamente a se realizar do modo mais acabado ao longo do tempo. Em Florestan, essa idéia do tipo para o qual sociedades complexas tendem de modo irreversível revelou-se das mais fecundas, quando empregada ao seu modo, como que a contrapelo: na identificação dos obstáculos que se opõem à plena realização da tendência objetiva. Sempre atento para o jogo das oportunidades estruturalmente abertas mas perdidas na ação dos agentes históricos, Florestan aproxima-se nisso de um traço marcante de outro grande contemporâneo seu, certamente mais "de cima" socialmente do que plebeu mas não visceralmente senhorial como Gilberto Freyre, o terceiro de um fascinante grupo de intérpretes do Brasil que se distribuíam por amplo espaço intelectual e social: Celso Furtado, para quem tantos momentos cruciais da formação e do desenvolvimento econômico do Brasil resultavam de atos falhos dos agentes decisivos. (Os outros dois, que completariam esse grupo, seriam Antonio Candido e Raymundo Faoro; algum dia alguém ainda há de traçar o retrato das formas de pensamento radical na época, do radicalismo plebeu de Florestan ao radicalismo senhorial de Freyre - uma primeira aproximação foi feita há exatos trinta anos por Carlos Guilherme Mota). No caso de Celso Furtado, o ponto a ser examinado, com relação a Florestan Fernandes, seria o da distinção entre a análise dos efeitos imprevistos de atos dotados de racionalidade no seu âmbito - de uma racionalidade imperfeita, portanto - em obras do primeiro, e a reconstrução, pelo segundo, da incapacidade estrutural de agentes históricos, como a burguesia brasileira saída na grande transição entre a condição colonial e a dependência, de aproveitarem oportunidades intrínsecas à sua condição de classe, que com isso também não se efetiva plenamente. (A questão, escreve Florestan em frase lapidar ao tratar do "desenvolvimento como problema nacional", tema caro a Furtado, é "compreender objetivamente por que um país colonial se converte numa nação dependente)".

Na perspectiva de Florestan, é essencial a tensão entre as tendências objetivas no sentido da plena realização de um determinado tipo de ordem social (burguesa, competitiva, capitalista no caso brasileiro) e os obstáculos de caráter histórico e estrutural que se antepõe a isso. É nela que se localizam as forças sociais em pugna pelo controle dos processos que darão à sociedade a sua feição 


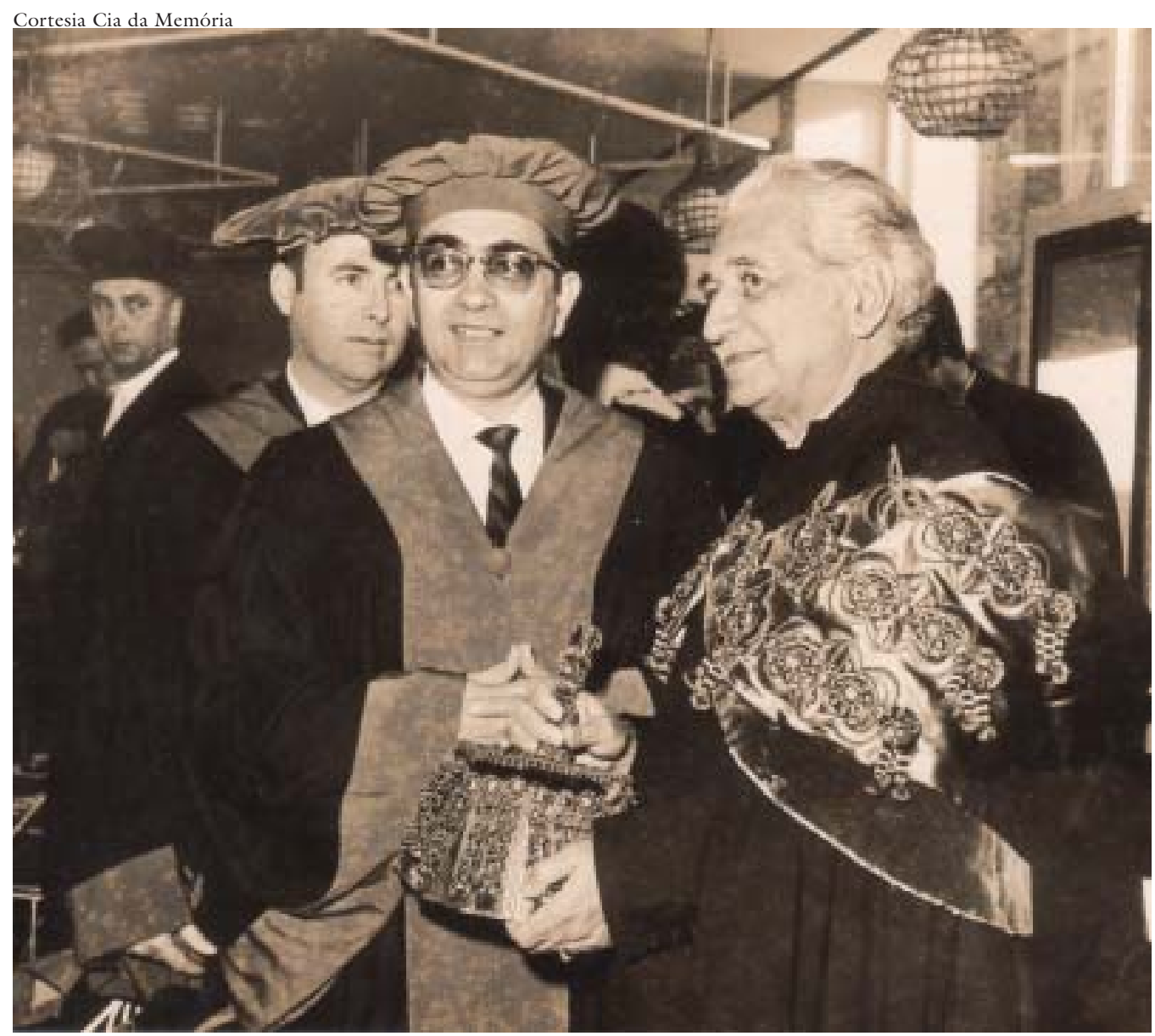

Encontro de sociólogos: Florestan Fernandes em cerimônia ao lado de Gilberto Freyre.

em cada etapa do seu desenvolvimento. A maneira que ele encontra para figurar esse jogo de forças na sua dinâmica própria não é a do embate puro e simples, mas a de relações que se movem em círculos, dotados - ou não, quando "viciosos" - de capacidade de desenvolvimento, formando circuitos abertos ou fechados (esta última modalidade, que identificou em momentos decisivos do caso brasileiro, deu título a um dos seus livros). Essa tensão é criativa, opõe-se a quaisquer processos de mera acomodação adaptativa, coisa que constitui seu mais fundo objeto de aversão. Revelando-se impossível a integração plena num padrão socialmente aceitável, não se completando os circuitos senão para bloquear o movimento seguinte, cabe trabalhar pela margem, já que o centro carece de força dinamizadora das oportunidades históricas, e fazer o que cabe a quem vem de fora sem ter o conforto de estar instalado de antemão: saturar as relações tensas entre as condições anteriores e os cenários futuros possíveis de sentidos para permitir a intervenção racional e não meramente voluntarista - até porque "o grau de racionalidade de uma ação social, seja ela econômica ou de outra natureza, depende da estrutura do campo em que o agente atua socialmente", como ele dizia em 1967 naquilo que viria a ser o seminal ensaio sobre sociedade de classes e desenvolvimento, publicado em 1972. 
Trabalhar na margem para vencer a condição marginal; visar ao centro sem instalar-se nele; buscar sempre identificar as condições objetivas para a aplicação de "técnicas democráticas de intervenção na realidade social" na busca de novas formas de organização compatíveis com a realização de todas as suas potencialidades, sem exceção - eis um belo e sério programa, longe de estar concluído.

Gabriel Cohn é professor do Departamento de Ciência Política da Faculdade de Filosofia, Letras e Ciências Humanas da USP e presidente da Anpocs (Associação Nacional de Pós-Graduação e Pesquisa em Ciências Sociais). @ - gcohn@uol.com.br

Recebido em 10.10.05 e aceito em 13.10.05. 